\title{
Erkenntnis Gibt es in der Philoso- phie (nicht nur) offene Fragen?
}

E ine offene Frage ist eine Frage, die noch nicht entschieden ist. Meine offene Frage ist, ob es in der Philosophie endgültige Entscheidungen von Fragen gibt. Auch wenn für mich selbst viele philosophische Fragen geklärt sind, so dürfte dies doch nicht für die Philosophie als solche zu gelten. In der Philosophie können wir nicht von einem Konsens der »wissenschaftlichen Gemeinschaft«ausgehen. Hier scheint jede Antwort neu in Frage gestellt werden zu können. Ein Anlass zu relativistischem Pessimismus erwächst daraus aber nicht: »Wir stehen nicht enttäuscht und sehn keineswegs betroffen / Den Vorhang zu und alle Fragen offen.« 